\title{
Reverse Analysis for Determining the Mechanical Properties of Zeolite Ferrierite Crystal
}

\author{
J. Lin, ${ }^{1}$ X. Y. Niu, ${ }^{2}$ and X. F. Shu ${ }^{2}$ \\ ${ }^{1}$ Department of Mechanic, North University of China, Taiyuan, Shanxi 030051, China \\ ${ }^{2}$ Research Institute of Applied Mechanics, Taiyuan University of Technology, Taiyuan, Shanxi 030024, China
}

Correspondence should be addressed to J. Lin, linjiang@nuc.edu.cn

Received 10 April 2008; Revised 22 September 2008; Accepted 7 December 2008

Recommended by Yapu Zhao

In order to explore more mechanical properties of zeolite Ferrierite (FER) single crystal, a method of determining its mechanical properties_nanoindentation reverse analysis_-was obtained based on the nanoindentation experiment and numerical simulations, and this will be presented in this paper. The yield stress and the characteristic work-hardening rate were gained if its stress-strain relation was a bilinear constitutive relation. The mechanical parameters obtained by reverse analysis have been compared with ones gained by nanoindentation finite-element numerical simulations.

Copyright (C) 2008 J. Lin et al. This is an open access article distributed under the Creative Commons Attribution License, which permits unrestricted use, distribution, and reproduction in any medium, provided the original work is properly cited.

\section{INTRODUCTION}

Nanoindentation experiments and finite-element numerical simulations are useful methods for the characterization of mechanical properties of thin film and very small-scale materials. The hardness and elastic modulus of micrometersized volumes can be known from a loading-unloading curve in the whole indented depth range according to the calculating method of Oliver and Pharr [1]. The mechanical behavior of single crystalline hydroxyapatite was examined through instrumented nano- and microindentation experiments on prism and basal planes by Viswanath et al. [2] Numerical simulations can give much information which is difficult to obtain from the nanoindentation experiment such as constitutive relation, yield stress, and yielded zone of materials though nanoindentation progress is very complex. In the recent years, Bolshakov et al. [3] investigated the influences of stress on the measurement of mechanical properties by both nanoindentation experimental studies and nanoindentation finite element simulations using special specimens of aluminum alloy 8009. Jayaraman et al. [4] measured and modeled the mechanical properties of the known 1070 steel by nanoindentation tests and finite element method, respectively. The results showed good agreement with the properties of the material. A work that was to combine numerical simulation and nanoindentation for determining mechanical properties of single crystal copper at mesoscale was done by Liu et al. [5]. In order to quantify the deformation characteristics of bulk metallic glass, Vaidyanathan et al. [6] carried out instrumented sharp indentation experiments at nano- and microlength scales. In the same time, detailed three-dimensional finite element simulations of instrumented indentation formulated an overall constitutive response. In addition, large deformation finite element computations were carried out for 76 different combinations of elastic-plastic properties for two aluminum alloys 6061-T6511 and 7075-T651 by Dao et al. [7]. Using dimensional analysis, forward and reverse analysis algorithms were established, elastic-plastic mechanical parameters of the two materials were obtained, and the computational results were compared with experimental data. Liu et al. [8] determined the mechanical properties of metallic foams with eighty different material parameters according to reverse analysis methods based on nanoindentation finite element simulations. Stauss et al. [9] obtained the stress-strain behavior of small devices such as thin films, coatings, and microelectromechanical systems by a reverse analysis of load-displacement data received from nanoindentation experiments. Y.-T. Cheng and C.M. Cheng [10, 11], Capehart and Y.-T. Cheng [12] used dimensional analysis and finite element calculations to derive several scaling relationships for conical indentation into 
elastic-perfectly plastic solids. They revealed the general relationships between hardness, contact area, initial unloading slope, and mechanical properties of solids. In 2004, Y.-T. Cheng and C.-M. Cheng provided an overview of the basic concepts of scaling and dimensional analysis and reviewed works of applying these concepts to modeling instrumented indentation measurements [13]. These methods are helpful as a guide to determine the mechanical properties of materials including small sizes. Kusano and Hutchings of the University of Cambridge made use of the method of Cheng to achieve hardness and modulus of carbon nitride films and silicon substrates. The data analysis of this method was compared with other methods. As Kusano said, "The method described by Y.-T. Cheng and C.-M. Cheng appears to provide the most reliable values for hardness and modulus for carbon nitride films" [14].

Zeolites are microporous crystalline solids with welldefined structures. It is well worth knowing their mechanical properties for their strength of design in their comprehensive applications. Because of strong compression and shear stress, their physical and chemical properties have been thoroughly investigated. Wang et al. $[15,16]$ measured to find Young's modulus of zeolite single crystal ZSM-5 (MFI) averaging about $200 \mu \mathrm{m}$ using a microdeformation tester made by themselves in 2002. Lin et al. [17, 18] tested the hardness and elastic modulus of zeolites FER and SOD of smaller sizes than ZSM-5 by nanoindentation experiments. Afterward, Brabec et al. [19] measured hardness and elastic modulus of zeolite silicalite-1 crystal twins from depthsensing indentations using Berkovich tip in 2006. In the same year, Lethbridge et al. [20] had a typical indentation experiment, in which they measured Young's moduli of the zeolite single-crystal natrolite, and comparison with dynamic studies and simulations. In 2006, Niu et al. [21] determined bilinear elastic-plastic constitutive relation of zeolite crystals FER and SOD.

In the present paper, based on the nanoindentation experiment and numerical simulations, the elastic-plastic bilinear constitutive relation of zeolite FER single crystal was gained using a nanoindentation reverse analysis method. The values of the mechanical parameters have been compared in between nanoindentation reverse analysis and finite-element numerical simulations.

\section{NANOINDENTATION REVERSE ANALYSIS OF ZEOLITE FERRIERITE SINGLE CRYSTAL}

Zeolite Ferrierite (FER) single crystal is a medium-pore-type zeolite, containing chains of five-membered rings, which are linked to give $5^{4}$ polyhedral units from which the threedimensional framework can be built. It contains a twodimensional network of 10 -MR pores $(4.3 \times 5.5 \AA)$ and 8 MR $(3.4 \times 5.5 \AA)$ intersecting channels [22]. Zeolite FER single crystal has been widely used as catalysts in chemistry reactions. For example, it may be used as catalyst of $n$ butene isomerization [23] and also can be employed as catalyst of NOx reduction [24]. Representative image of zeolite FER single crystal was displayed in Figure 1(a), and the framework structure was played in Figure 1(b). From this

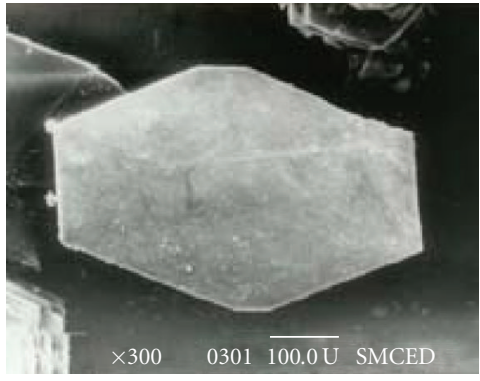

(a) The image of zeolite FER

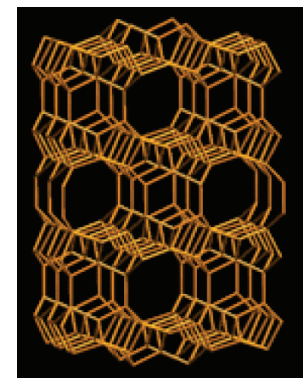

(b) The framework structure of zeolite FER
Figure 1: The image and framework structure of typical sample of zeolite FER single crystal.

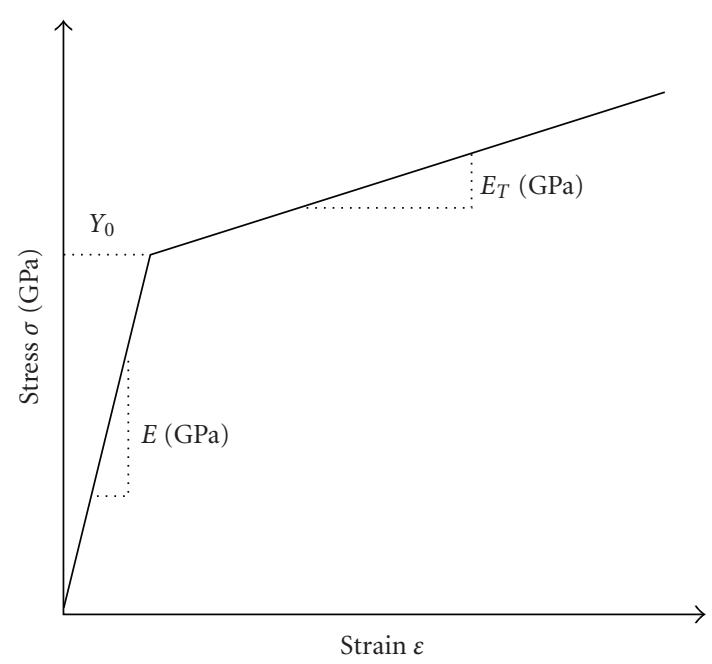

FIGURE 2: Elastic-plastic bilinear stress-strain curve for zeolite FER single crystal.

image, we can see that the shape of zeolite FER single crystal is flaky about $290 \times 180 \mu \mathrm{m}$.

\subsection{Calculation of nanoindentation finite-element numerical simulations of zeolite FER single crystal}

The elastic-plastic bilinear material model was presented. Now, we must make finite element numerical simulation for zeolite FER single crystal before the calculation of reverse analysis. A schematic representation of the bilinear constitutive law was shown in Figure 2 [25].

The elastic-plastic stress-strain behavior of zeolite FER single crystal was given by the expression

$$
\sigma= \begin{cases}E \mathcal{E}, & \varepsilon \leq \varepsilon_{0} \\ \sigma_{0}+E_{T} \varepsilon, & \varepsilon>\varepsilon_{0}\end{cases}
$$

where $E$ was the elastic modulus, and $E_{T}$ was the characteristic work-hardening rate. $\sigma_{0}$ and $\varepsilon_{0}$ were the corresponding stress and strain values, respectively, when the material reached the yield. 


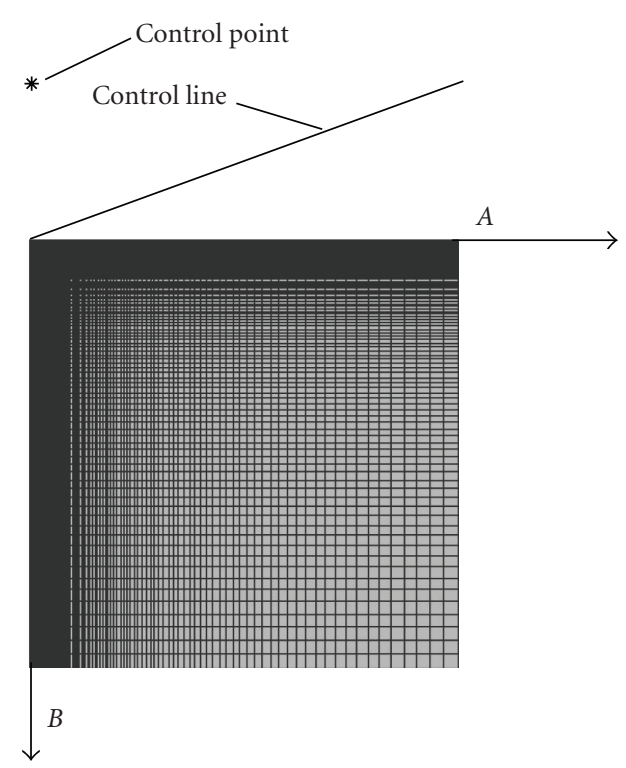

Figure 3: The finite element mesh of the indentation process for zeolite FER single crystal.

Because of the axisymmetrical structure of zeolite FER single crystal, axisymmetrical material and conical rigid indenter were used in the finite element in place of the triangular Berkovich indenter used in the experimental study where had a real deformation field. In order to simplify the sample model, the half-included tip angle of the conical indenter was $70.3^{\circ}$, giving the sample depth-to-area ratio as the Berkovich pyramid used in the experiments [25].

Simultaneous control point and control line were used for simulating the shape of indenter. The model was determined as a square of $35 \times 35 \mu \mathrm{m}$ because of the indentation depth $1100.2 \mathrm{~nm}$ when the load's peak value in the experiment had no influence on the result. The typical axisymmetric geometry and mesh used in the study were shown in Figure 3.

It was known that the mechanical properties of zeolite FER single crystal were confirmed from the parameters $E, \sigma_{0}$, $E_{T}$ in (1). Yield stress $\sigma_{0}$ was chosen at the range of 0.067$0.938 \mathrm{GPa}$, and there were six values. If the characteristic work-hardening rate $E_{T}$ was chosen at the range of 0.03$0.5 \mathrm{GPa}$, three values were assumed as shown in Table 1 . So, eighteen group parameters were constructed, and eighteen group load-displacement curves were obtained through calculating nanoindentation finite-element numerical simulations in which Yuong's modulus of zeolite FER single crystal was $10 \mathrm{GPa}$ from the nanoindentation experiment [17]. Its Poisson's ratio was 0.25 for a $5 \%$ error range when the Poisson's ratio of any material was not known for nanoindentation.

Calculating data of eighteen groups $C$ and $h_{r} / h_{m}$ were obtained from eighteen load-displacement curves like Figure 6 through the nanoindentation finite-element numerical simulations (in Table 2). $C$ was the indentation curvature, a measure of the "resistance" of the material to indentation (referring to relation 17). $h_{r}$ was final
TABLE 1: The mechanics properties of zeolite FER single crystal used in the finite-element numerical simulations.

\begin{tabular}{lccccc}
\hline$E(\mathrm{GPa})$ & $\sigma_{0}(\mathrm{GPa})$ & $E^{\bullet} / \sigma_{0}$ & $\sigma_{0} / E^{*}$ & $E_{T}(\mathrm{GPa})$ & $E_{T} / E^{*}$ \\
\hline 10 & 0.067 & 159.3 & 0.0063 & 0.03 & 0.0028 \\
10 & 0.085 & 125.5 & 0.008 & 0.08 & 0.0075 \\
10 & 0.117 & 91.2 & 0.011 & 0.5 & 0.047 \\
10 & 0.188 & 56.76 & 0.0176 & & \\
10 & 0.47 & 22.7 & 0.044 & & \\
10 & 0.938 & 11.38 & 0.0879 & & \\
\hline
\end{tabular}

TABLe 2: 18 groups $C$ and $h_{r} / h_{m}$ values through calculation of nanoindentation finite-element numerical simulations of zeolite FER single crystal.

\begin{tabular}{lcccc}
\hline$C(\mathrm{GPa})$ & $C(\mathrm{GPa})$ & $h_{r} / h_{m}$ & $h_{r} / h_{m}$ & $E_{T}(\mathrm{GPa})$ \\
\hline 5.36 & 6.40 & 0.872 & 0.861 & 0.03 \\
8.04 & 10.43 & 0.823 & 0.773 & 0.03 \\
15.79 & 19.42 & 0.622 & 0.433 & 0.03 \\
5.45 & 6.47 & 0.865 & 0.845 & 0.08 \\
8.03 & 10.55 & 0.825 & 0.776 & 0.08 \\
15.75 & 19.45 & 0.626 & 0.435 & 0.08 \\
6.16 & 6.80 & 0.815 & 0.805 & 0.5 \\
8.42 & 10.6 & 0.795 & 0.755 & 0.5 \\
16.11 & 19.51 & 0.605 & 0.435 & 0.5 \\
\hline
\end{tabular}

indentation depth after unloading, and $h_{m}$ was indentation depth at peak load (referring to Figure 6).

\subsection{The determining connections of yield strength $\sigma_{0}$ and characteristic work-hardening rate $E_{T}$ for zeolite FER single crystal}

Formula (2) was expressed according to the $\Pi$ theorem in dimensional analysis [7] and (1) during loading:

$$
\frac{C}{\sigma_{0}}=\Pi_{1}\left(\frac{E^{*}}{\sigma_{0}}, \frac{E_{T}}{E^{*}}\right) .
$$

During unloading process, it was expressed as

$$
P_{x}=E^{*} h^{2} \Pi_{2}\left(\frac{h_{m}}{h}, \frac{\sigma_{0}}{E^{*}}, \frac{E_{T}}{E^{*}}\right),
$$

when $P_{x}=0, h=h_{r}$, (3) became

$$
\frac{h_{r}}{h_{m}}=\Pi_{3}\left(\frac{\sigma_{0}}{E^{*}}, \frac{E_{T}}{E^{*}}\right),
$$

where $P_{x}$ was the unloading force, and $h_{r}$ was final indentation depth after unloading. $h_{m}$ was indentation depth at peak load (referring to Figure 6). $E^{*}$ was composite elastic modulus. $T E^{*} / \sigma_{0}-C / \sigma_{0}$ curves can be obtained when the characteristic work-hardening rate is $E_{T}=0.03$ for $\left(E_{T} / E^{*}\right)=0.0028, E_{T}=0.08$ for $\left(E_{T} / E^{*}\right)=0.0075$, and $E_{T}=0.5$ for $\left(E_{T} / E^{*}\right)=0.047$ separately (see Figure 4$)$ according to the data of Tables 1 and 2 .

When $\left(E_{T} / E^{*}\right)=0.0028, \Pi_{1}$ was

$$
\frac{C}{\sigma_{0}}=\Pi_{1}\left(\frac{E^{*}}{\sigma_{0}}, \frac{E_{T}}{E^{*}}\right)=23.135 \ln \left(\frac{E^{*}}{\sigma_{0}}\right)-36.978 .
$$




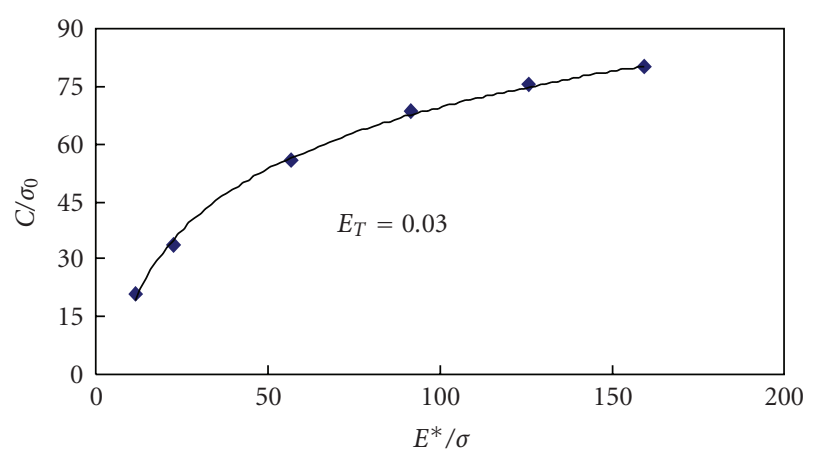

- Simulated data

- Fitting curve

(a) Dimensionless function $\Pi_{1}$, when $E_{T}=0.03$

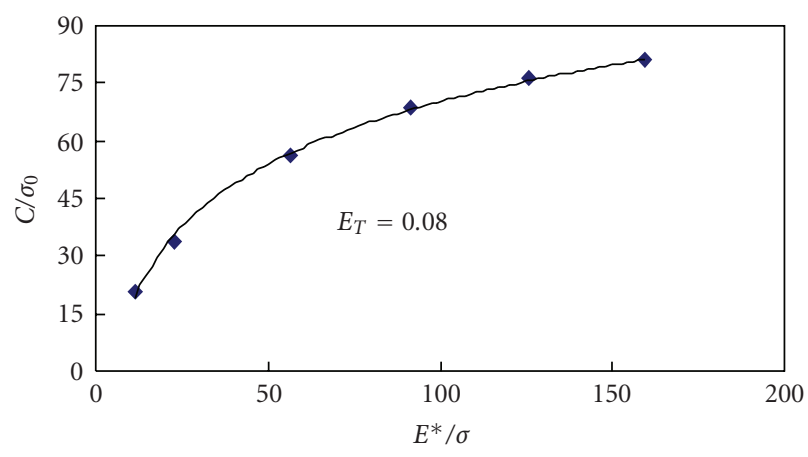

- Simulated data

- Fitting curve

(b) Dimensionless function $\Pi_{1}$, when $E_{T}=0.08$

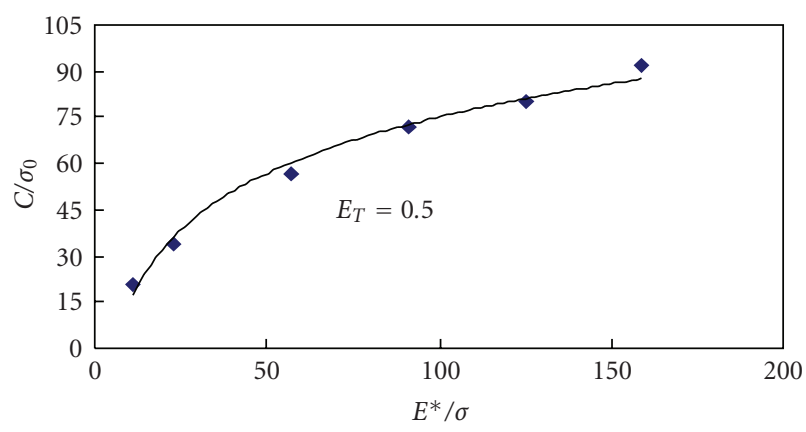

- Simulated data

- Fitting curve

(c) Dimensionless function $\Pi_{1}$, when $E_{T}=0.5$

FIgURE 4: Dimensionless function $C / \sigma_{0}=\Pi_{1}\left(E^{*} / \sigma_{0}\right)$ obtained by the finite element simulations for zeolite FER single crystal.

When $\left(E_{T} / E^{*}\right)=0.0075, \Pi_{1}$ was

$$
\frac{C}{\sigma_{0}}=\Pi_{1}\left(\frac{E^{*}}{\sigma_{0}}, \frac{E_{T}}{E^{*}}\right)=23.519 \ln \left(\frac{E^{*}}{\sigma_{0}}\right)-38.054 .
$$

When $\left(E_{T} / E^{*}\right)=0.047, \Pi_{1}$ was

$$
\frac{C}{\sigma_{0}}=\Pi_{1}\left(\frac{E^{*}}{\sigma_{0}}, \frac{E_{T}}{E^{*}}\right)=26.5 \ln \left(\frac{E^{*}}{\sigma_{0}}\right)-46.878 .
$$

Zeolite FERs dimensionless function $\Pi_{1}$ was

$$
\frac{C}{\sigma_{0}}=\Pi_{1}\left(\frac{E^{*}}{\sigma_{0}}, \frac{E_{T}}{E^{*}}\right)=A \ln \left(\frac{E^{*}}{\sigma_{0}}\right)+B .
$$

Fitting the coefficient before $\ln \left(E^{*} / \sigma_{0}, E_{T} / E^{*}\right)$ in functions (5), (6), and (7), we gained

$$
A=75.87\left(\frac{E_{T}}{E^{*}}\right)+22.94 .
$$

Fitting the second item in functions (5), (6), and (7), we gained

$$
B=-223.75\left(\frac{E_{T}}{E^{\bullet}}\right)-36.36 .
$$

$\left(E^{*} / \sigma_{0}\right)$ was in the range of $11.38-159.3$ (see Table 1 ), and $\left(E_{T} / E^{*}\right)$ was in the range of $0.0028-0.047$. Therefore, (8), (9), and (10) expressed dimensionless function $\Pi_{1}$ for zeolite FER single crystal in total.

From Tables 1 and 2, we also can obtain $h_{r} / h_{m}-\sigma_{0} / E^{*}$ curves (see Figure 5), when $\left(E_{T} / E^{*}\right)=0.0028,\left(E_{T} / E^{*}\right)=$ 0.0075 , and $\left(E_{T} / E^{*}\right)=0.047$, respectively.

When $\left(E_{T} / E^{*}\right)=0.0028, \Pi_{2}$ was

$$
\frac{h_{r}}{h_{m}}=\Pi_{2}\left(\frac{\sigma_{0}}{E^{*}}, \frac{E_{T}}{E^{*}}\right)=-0.1634 \ln \left(\frac{\sigma_{0}}{E^{*}}\right)+0.0769 .
$$

When $\left(E_{T} / E^{*}\right)=0.0075, \Pi_{2}$ was

$$
\frac{h_{r}}{h_{m}}=\Pi_{2}\left(\frac{\sigma_{0}}{E^{*}}, \frac{E_{T}}{E^{*}}\right)=-0.1584 \ln \left(\frac{\sigma_{0}}{E^{*}}\right)+0.0948 .
$$

When $\left(E_{T} / E^{*}\right)=0.047, \Pi_{2}$ was

$$
\frac{h_{r}}{h_{m}}=\Pi_{2}\left(\frac{\sigma_{0}}{E^{*}}, \frac{E_{T}}{E^{*}}\right)=-0.1426 \ln \left(\frac{\sigma_{0}}{E^{*}}\right)+0.1311 .
$$

Zeolite FERs dimensionless function $\Pi_{2}$ was

$$
\frac{h_{r}}{h_{m}}=\Pi_{2}\left(\frac{\sigma_{0}}{E^{*}}, \frac{E_{T}}{E^{*}}\right)=A \ln \left(\frac{\sigma_{0}}{E^{*}}\right)+B .
$$

Using the same method previously, fitting the coefficient before $\ln \left(E^{*} / \sigma_{0}, E_{T} / E^{*}\right)$ and the second items in functions (11), (12), and (13), respectively, we gained

$$
\begin{aligned}
& A=-15.02\left(\frac{E_{T}}{E^{*}}\right)^{2}+1.22\left(\frac{E_{T}}{E^{*}}\right)-0.1667, \\
& A=-65.37\left(\frac{E_{T}}{E^{*}}\right)^{2}+4.48\left(\frac{E_{T}}{E^{*}}\right)+0.065,
\end{aligned}
$$

$\left(\sigma_{0} / E^{*}\right)$ is in the range of $0.0063-0.0879$ (see Table 1 ), and $\left(E_{T} / E^{*}\right)$ is in the range of $0.0028-0.047$. As a result, (14), (15) have expressed dimensionless function $\Pi_{2}$ for zeolite FER single crystal in total. 


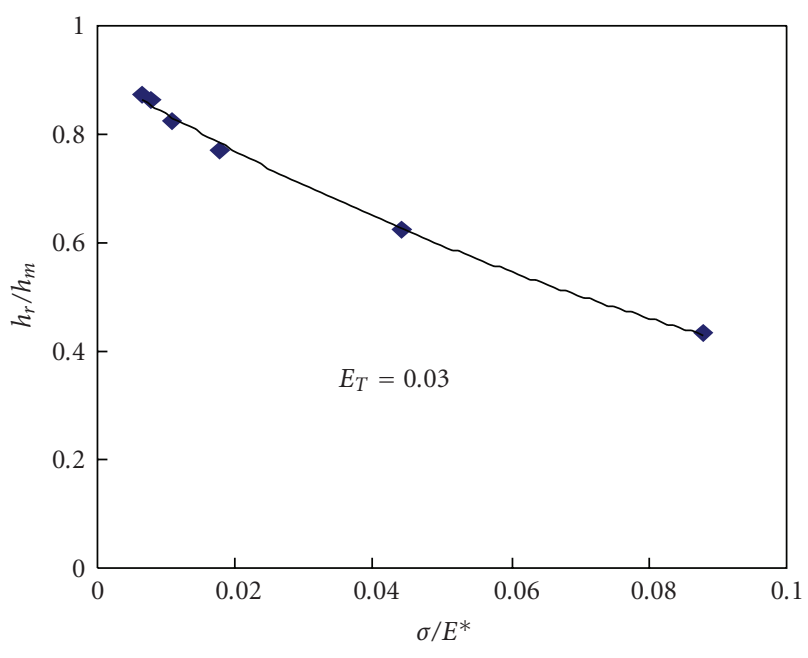

- Simulated data Fitting curve

(a) Dimensionless function $\Pi_{2}$, when $E_{T}=0.03$

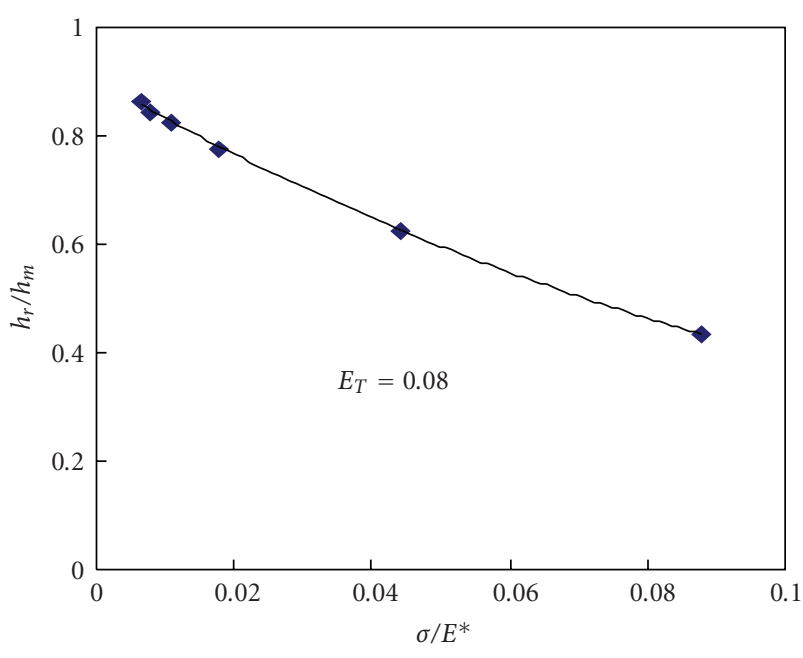

- Simulated data Fitting curve

(b) Dimensionless function $\Pi_{2}$, when $E_{T}=0.08$

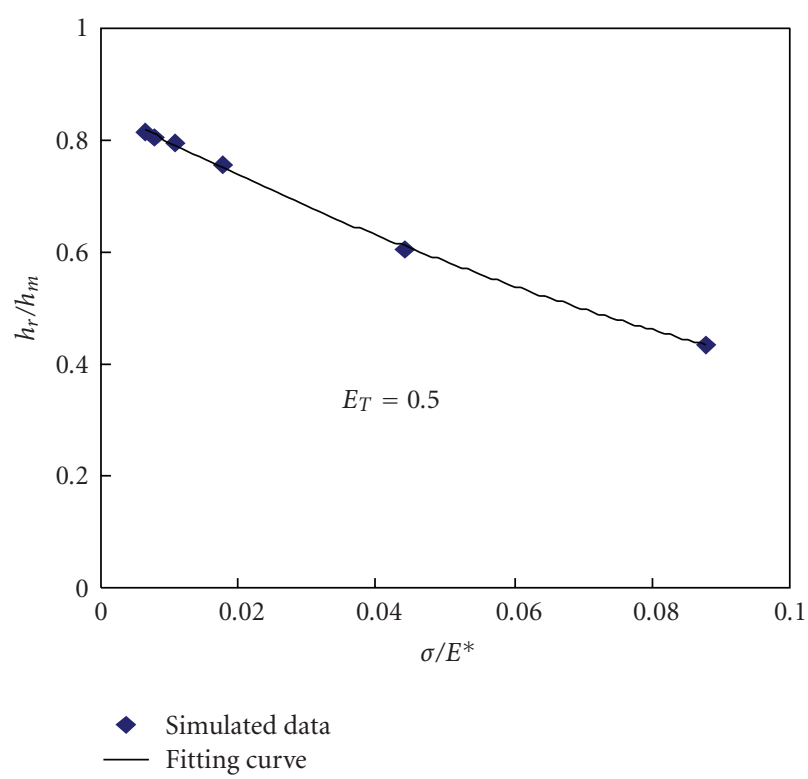

(c) Dimensionless function $\Pi_{2}$, when $E_{T}=0.5$

FIGURE 5: Dimensionless function $h_{r} / h_{m}=\Pi_{2}\left(\sigma_{0} / E^{*}\right)$ obtained by the finite element simulations for zeolite FER single crystal.

\subsection{The calculation of mechanical parameters of zeolite FER single crystal}

Figure 6 was load-displacement curve of zeolite FER that Lin et al. [17] acquired from nanoindentation experiment. During loading, the curve generally followed the relation [7]

$$
P=C h^{2},
$$

where $P$ represented the load, and $C$ was the indentation curvature which was a measure of the "resistance" of the material to indentation. $C$ and $h_{r} / h_{m}$ were independent quantities that can be directly found from a load-displacement curve without any change if materials were defined according to the discussion of Giannakopoulos and Suresh [26]. From the experimental curve of zeolite FER (see Figure 6), we can know independent quantities $C=9.86 \mathrm{GPa}$, that is, $P=9.86 h^{2}, h_{r} / h_{m}=0.5975$, and elastic modulus was $10 \mathrm{GPa}$ from the literature [17]. According to contact mechanics and Berkovich indenter (three-sided pyramid) being made of diamond material, the expression of composite elastic modulus was seen as follows:

$$
E^{*}=\frac{E}{1-\gamma^{2}}=\frac{10}{1-0.25^{2}}=10.67
$$

where $\gamma$ was the material's Poisson's ratio. 


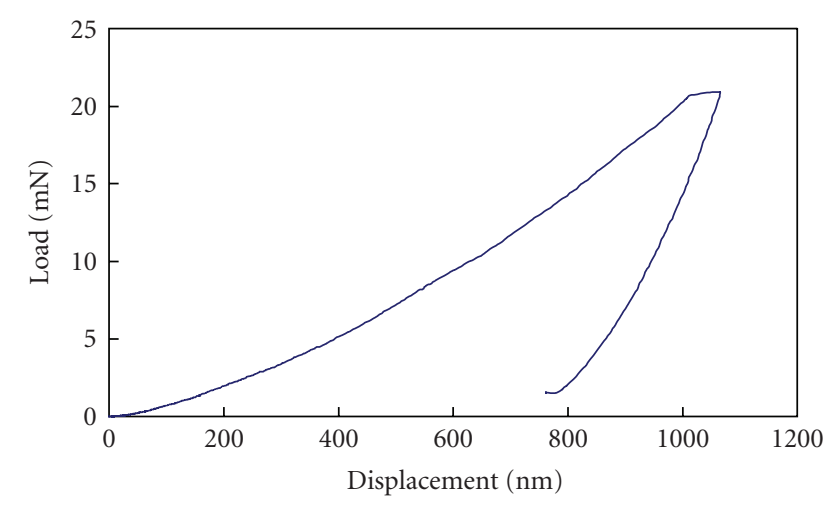

FIGURE 6: Load-displacement curve of zeolite FER in nanoindentation experiment.

From formula (8), we can get

$$
\frac{9.86 \times 10^{9}}{\sigma_{0}}=A \ln \left(\frac{10.67 \times 10^{9}}{\sigma_{0}}\right)+B,
$$

and from expression (14), we can get

$$
0.5975=A \ln \left(\frac{\sigma_{0}}{10.67 \times 10^{9}}\right)+B .
$$

Two-group results of yield stress $\sigma_{0}$ and the characteristic work-hardening rate $E_{T}$ were been obtained by solving the group equations (9), (10), (18) and (15), (19) using MATLAB program:

$$
\begin{array}{cl}
\sigma_{0} & =0.1509, \quad \sigma_{0}=0.5227, \\
E_{T} & =0.4318,
\end{array}
$$

In the two results, only $\sigma_{0}=0.1509, E_{T}=0.4318$ can meet the demand because $3.2<\ln \left(E^{*} / \sigma_{0}\right)<5$ is according to Figure 4 or Table 1 . So yield stress $\sigma_{0}$ and the characteristic work-hardening rate $E_{T}$ of zeolite FER single crystal were $0.1509 \mathrm{GPa}$ and $0.4318 \mathrm{GPa}$, respectively, using nanoindentation reverse analysis method.

Therefore, the stress-strain relation was

$$
\sigma= \begin{cases}10 \varepsilon, & \varepsilon \leq 0.018 \\ 0.1509+0.4318 \varepsilon, & \varepsilon>0.018\end{cases}
$$

\subsection{The comparison of zeolite FER single crystal between the reverse algorithm and the finite-element numerical simulations}

We know that the bilinear constitutive law of zeolite FER single crystal is shown in (22) through nanoindentation finite-element numerical simulations [21]:

$$
\sigma= \begin{cases}10 \varepsilon, & \varepsilon \leq 0.018 \\ 0.18+0.5 \varepsilon, & \varepsilon>0.018\end{cases}
$$

This relation was compared with (21), and it was known that the yield strength and the characteristic work-hardening rate were approximated in the finite element simulation to the ones in the reverse algorithm. This phenomenon accounted for the reliability of these two calculating methods of determining mechanical properties of zeolite FER single crystal.

Though hardness and elastic modulus can be obtained alone in the nanoindentation experiment, the question of whether the stress-strain relationships of FER single crystal can be uniquely determined by matching the calculated loading and unloading curves with that measured experimentally remains to be investigated. The possibilities of using several conical indenters of different angles to obtain stress-strain relationships should also be investigated both experimentally and theoretically $[27,28]$. This work will be continued.

\section{CONCLUSIONS}

In order to determine the mechanical properties of small size zeolites FER single crystal, a new method, reverse analysis, was put forward. This method has been carried out with eighteen different material parameters for zeolite FER single crystal based on bilinear modeling. The calculative results in conjunction with the dimensionless analysis method were used to establish the relationship between the cone indentation behavior and the elastic-plastic material parameters of zeolite FER single crystal. The result was to obtain its yield stress and the characteristic work-hardening rate being $0.1509 \mathrm{GPa}$ and $0.4318 \mathrm{GPa}$, respectively. Two methods between reverse analysis and finite element simulations were compared, and the yield stress and the characteristic workhardening rate were consistent for zeolite FER single crystal. Obtained results showed that the mechanical properties of zeolite FER single crystal can be unambiguously determined assuming bilinear constitutive relations by the developed nanoindentation reverse analysis method. Therefore, the reverse analysis method gave a good guideline for the determination of constitutive behavior of zeolite FER single crystal. Furthermore, this technique is a potential method for researching mechanical properties of more zeolites and other small volume materials.

\section{REFERENCES}

[1] W. C. Oliver and G. M. Pharr, "An improved technique for determining hardness and elastic modulus using load and displacement sensing indentation experiments," Journal of Materials Research, vol. 7, no. 6, pp. 1564-1583, 1992.

[2] B. Viswanath, R. Raghavan, U. Ramamurty, and N. Ravishankar, "Mechanical properties and anisotropy in hydroxyapatite single crystals," Scripta Materialia, vol. 57, no. 4, pp. 361364, 2007.

[3] A. Bolshakov, W. C. Oliver, and G. M. Pharr, "Influences of stress on the measurement of mechanical properties using nanoindentation-part II. Finite element simulations," Journal of Materials Research, vol. 11, no. 3, pp. 760-768, 1996.

[4] S. Jayaraman, G. T. Hahn, W. C. Oliver, C. A. Rubin, and P. C. Bastias, "Determination of monotonic stress-strain curve of hard materials from ultra-low-load indentation tests," International Journal of Solids and Structures, vol. 35, no. 5-6, pp. 365-381, 1998. 
[5] Y. Liu, B. Wang, M. Yoshino, S. Roy, H. Lu, and R. Komanduri, "Combined numerical simulation and nanoindentation for determining mechanical properties of single crystal copper at mesoscale," Journal of the Mechanics and Physics of Solids, vol. 53, no. 12, pp. 2718-2741, 2005.

[6] R. Vaidyanathan, M. Dao, G. Ravichandran, and S. Suresh, "Study of mechanical deformation in bulk metallic glass through instrumented indentation," Acta Materialia, vol. 49, no. 18, pp. 3781-3789, 2001.

[7] M. Dao, N. Chollacoop, K. J. Van Vliet, T. A. Venkatesh, and S. Suresh, "Computational modeling of the forward and reverse problems in instrumented sharp indentation," Acta Materialia, vol. 49, no. 19, pp. 3899-3918, 2001.

[8] C. Liu, C. Q. Chen, and Y. P. Shen, "Numerical simulation for cone indentation of metallic foams and the reverse analysis," Chinese Journal of Theoretical and Applied Mechanics, vol. 38, no. 2, pp. 176-184, 2006.

[9] S. Stauss, P. Schwaller, J.-L. Bucaille, et al., "Determining the stress-strain behaviour of small devices by nanoindentation in combination with inverse methods," Microelectronic Engineering, vol. 67-68, pp. 818-825, 2003.

[10] Y.-T. Cheng and C.-M. Cheng, "Scaling relationships in conical indentation of elastic-perfectly plastic solids," International Journal of Solids and Structures, vol. 36, no. 8, pp. 1231-1243, 1999.

[11] Y.-T. Cheng and C.-M. Cheng, "What is indentation hardness?" Surface and Coatings Technology, vol. 133-134, pp. 417424, 2000.

[12] T. W. Capehart and Y.-T. Cheng, "Determining constitutive models from conical indentation: sensitivity analysis," Journal of Materials Research, vol. 18, no. 4, pp. 827-832, 2003.

[13] Y.-T. Cheng and C.-M. Cheng, "Scaling, dimensional analysis, and indentation measurements," Materials Science and Engineering $R$, vol. 44, no. 4-5, pp. 91-149, 2004.

[14] Y. Kusano and I. M. Hutchings, "Analysis of nano-indentation measurements on carbon nitride films," Surface and Coatings Technology, vol. 169-170, pp. 739-742, 2003.

[15] Z. Wang, J. Lambros, and R. F. Lobo, "Micromechanical compressive response of a zeolite single crystal," Journal of Materials Science, vol. 37, no. 12, pp. 2491-2499, 2002.

[16] Z. Wang, R. F. Lobo, and J. Lambros, "The mechanical properties of siliceous ZSM-5 (MFI) crystals," Microporous and Mesoporous Materials, vol. 57, no. 1, pp. 1-7, 2003.

[17] J. Lin, X. F. Shu, and J. X. Dong, "The experimental determination of mechanical properties of zeolite ferrierite crystal," Materials Letters, vol. 59, no. 12, pp. 1595-1597, 2005.

[18] J. Lin, X. F. Shu, and J. X. Dong, "The synthesis and mechanical properties of large zeolite sodalite single crystals," Studies in Surface Science and Catalysis, vol. 158, part 1, pp. 231-238, 2005.

[19] L. Brabec, P. Bohac, M. Stranyanek, R. Ctvrtlik, and M. Kocirik, "Hardness and elastic modulus of silicalite-1 crystal twins," Microporous and Mesoporous Materials, vol. 94, no. 13, pp. 226-233, 2006.

[20] Z. A. D. Lethbridge, J. J. Williams, R. I. Walton, C. W. Smith, R. M. Hooper, and K. E. Evans, "Direct, static measurement of single-crystal Young's moduli of the zeolite natrolite: comparison with dynamic studies and simulations," Acta Materialia, vol. 54, no. 9, pp. 2533-2545, 2006.

[21] X. Y. Niu, J. Lin, and X. F. Shu, "The determination of bilinear elastic-plastic constitutive relation of zeolite crystals," Acta Mechanica Solida Sinica, vol. 27, no. 4, pp. 394-398, 2006.
[22] R. B. Khomane, B. D. Kulkarni, and R. K. Ahedi, "Synthesis and characterization of ferrierite-type zeolite in the presence of nonionic surfactants," Journal of Colloid and Interface Science, vol. 236, no. 2, pp. 208-213, 2001.

[23] L. Domokos, L. Lefferts, K. Seshan, and J. A. Lercher, "The importance of acid site locations for $n$-butene skeletal isomerization on ferrierite," Journal of Molecular Catalysis A, vol. 162, no. 1-2, pp. 147-157, 2000.

[24] C. Montes de Correa, F. Córdoba, and F. Bustamante, “The role of zeolite type on the lean $\mathrm{NO}_{x}$ reduction by methane over Pd loaded pentasil zeolites," Microporous and Mesoporous Materials, vol. 40, no. 1-3, pp. 149-157, 2000.

[25] H. Pelletier, J. Krier, A. Cornet, and P. Mille, "Limits of using bilinear stress-strain curve for finite element modeling of nanoindentation response on bulk materials," Thin Solid Films, vol. 379, no. 1-2, pp. 147-155, 2000.

[26] A. E. Giannakopoulos and S. Suresh, "Determination of elastoplastic properties by instrumented sharp indentation," Scripta Materialia, vol. 40, no. 10, pp. 1191-1198, 1999.

[27] Y.-T. Cheng and C.-M. Cheng, "Can stress-strain relationships be obtained from indentation curves using conical and pyramidal indenters?" Journal of Materials Research, vol. 14, no. 9, pp. 3493-3496, 1999.

[28] Y.-T. Cheng, Z. Li, and C.-M. Cheng, "Scaling relationships for indentation measurements," Philosophical Magazine A, vol. 82, no. 10, pp. 1821-1829, 2002. 

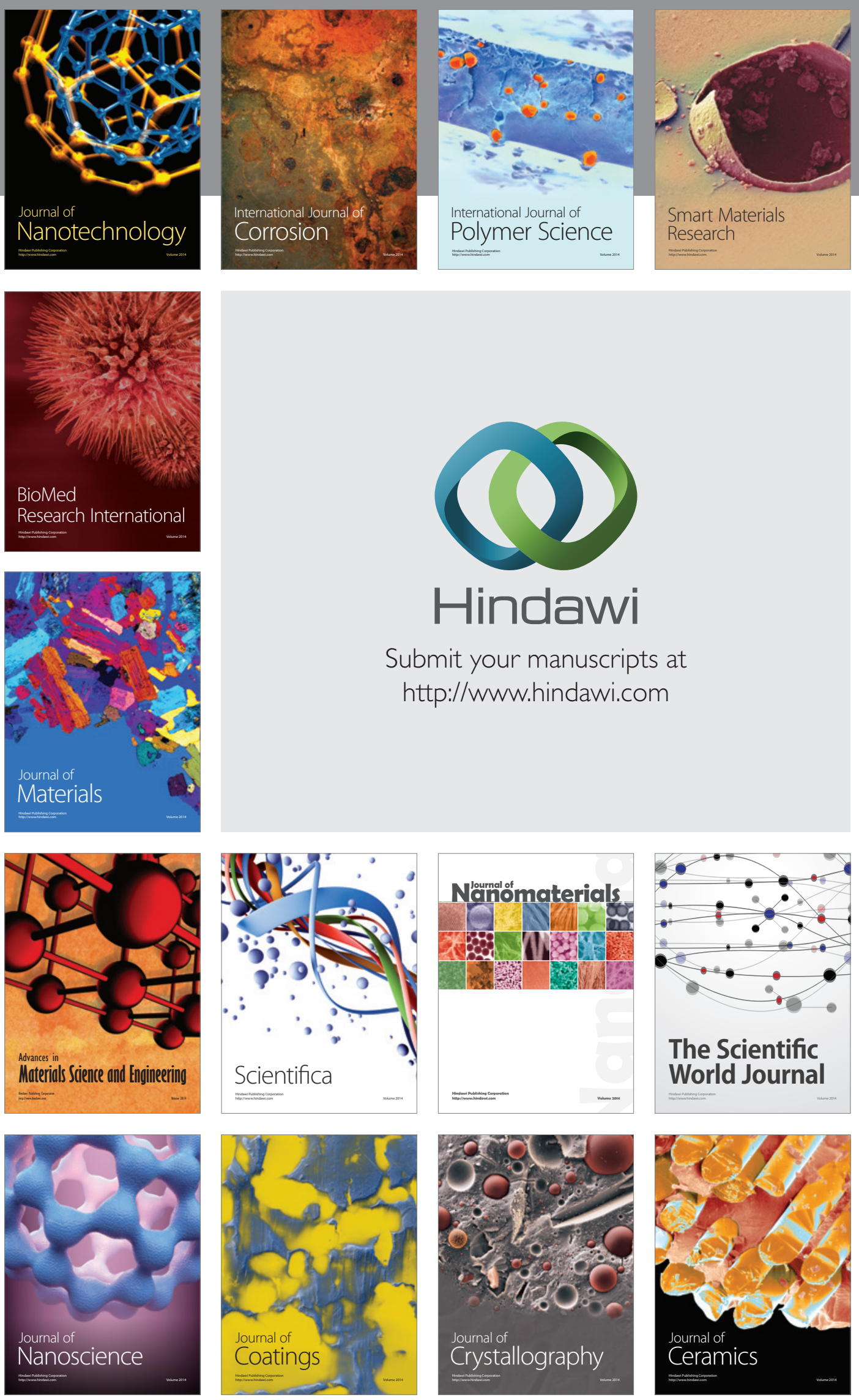

The Scientific World Journal

Submit your manuscripts at

http://www.hindawi.com

\section{World Journal}

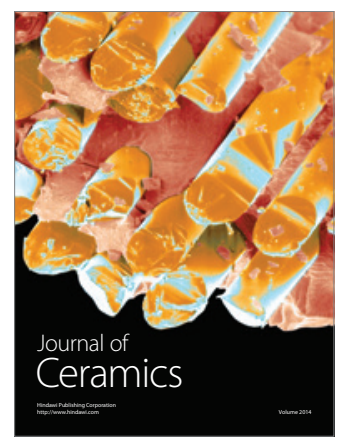

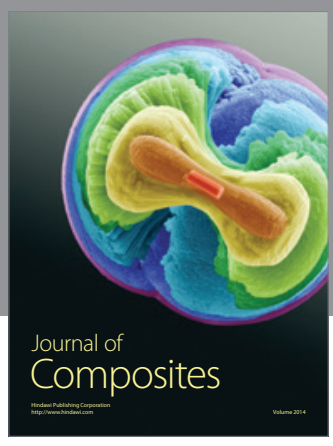
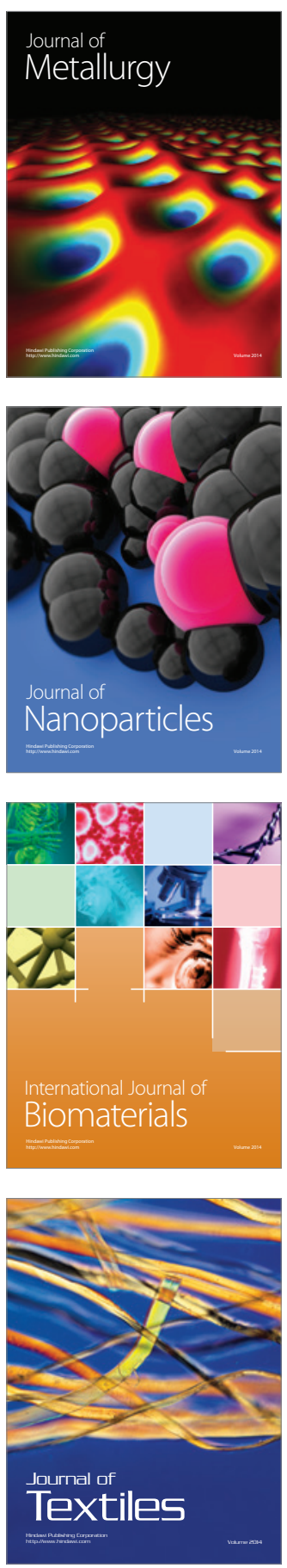